Pak. j. sci. ind. res. Ser. B: biol. sci. 2019 62B(1) 24-32

\title{
Comparative Physicochemical and Microbiological Assessment of Branded and Unbranded Whole Wheat Flours in Pakistan
}

\author{
Khurram Shahzad $^{\mathrm{a}}$, Shaista Nawaz ${ }^{\mathrm{a}}$, Saba Zahid ${ }^{\mathrm{b}}$, Salman Saeed ${ }^{\mathrm{a}}$, Yasar Saleem ${ }^{\mathrm{a}}$, \\ Abdul Ahid Rashida ${ }^{a}$, Abida Hassan ${ }^{c}$ and Sajid Husain ${ }^{a}$ \\ ${ }^{a}$ Food and Biotechnology Research Center, PCSIR Laboratories Complex, Lahore-54600, Pakistan \\ ${ }^{b}$ Department of Food and Nutrition, Govt. College of Home-Economics Lahore, Pakistan \\ ${ }^{\mathrm{c}}$ Higher Education Department, Government of Punjab, Lahore, Pakistan
}

(received July 10, 2017; revised January 23, 2018; accepted February 23, 2018)

\begin{abstract}
Wheat flour is the main cereal food consumed in Pakistan. Cereal industry and cereal based products have a great social and economic global impact. The present study aims to investigate the comparative nutritional composition, storage stability and microbiological quality of branded and unbranded whole wheat flours available in the local market of Lahore, Pakistan along with the assessment of impurity content. Nutritional composition (macro nutrients and iron content), microbiological quality (yeast and mould count) and possible impurity contents were determined using the standard methods. The results revealed that both branded and unbranded whole wheat showed satisfactory nutritional and storage quality, however, microbiological quality of branded whole wheat flour was better than unbranded whole wheat flour. Moreover, selected samples of branded whole wheat flour neither showed contamination nor presence of impurity. Ash content and microbial (yeast) count of some samples of unbranded whole wheat flour indicated contamination. However, overall results did not support presence of impurity content. Further research is required to determine the vitamin and mineral contents of branded and unbranded whole wheat flour to improve the nutritional quality of flour for combating malnutrition in Pakistan.
\end{abstract}

Keywords: microbiological quality, nutritional assessment, wheat flour, storage quality

\section{Introduction}

Cereals and cereal by-products comprise a significant food supply for the world's population. Among cereals, Wheat (Triticum aestivum L.), a member of family Poaceae, is a vital food crop for a large segment of the world population. It is the cheapest and major source of proteins and calories that provides almost $73 \%$ of these nutrients in the average diet (FAO, 1994). The net dietary protein calories of wheat bread are $5.9 \%$ and can fulfill the daily need of protein of an adult if consumed in an adequate quantity (Saeid et al., 2015). Wheat is also a good source of vitamins B1, B2, B6, niacin as well as iron and zinc in its natural state. But since most of these nutrients are concentrated in the outer layer of wheat grain, a significant portion is lost during roller milling process. For more refined wheat flour, the loss of minerals and vitamins is greater as in modern milling sector.

Wheat is a leading grain crop of Pakistan and an important dietary staple consumed by Pakistani people (ESP, 2010). Wheat flour constitutes a major portion of daily diet of rural as well as urban population of

\footnotetext{
*Author for correspondence; E-mail: snpcsir1@hotmail.com
}

Pakistan and currently contributing $72 \%$ of daily caloric intake presenting around $124 \mathrm{~kg} /$ year per capita wheat consumption, one of the highest in the world (USDA, 2014). Pakistan produces an average of 22 to 26 million tonnes of wheat a year (FAO, 2013).

Wheat is mostly milled to whole-wheat flour in Pakistan for the manufacturing of unleavened flat bread locally known as "Chapatti" (ESP, 2010; Nasir et al., 2003). Wheat kernel is a store house of nutrients essential to the human diet. It contains $80-85 \%$ endosperm; 13 $17 \%$ bran and $2-3 \%$ germ, all contribute to the nutritional content of the grain (Belderok et al., 2000). Wholewheat flour is a coarse-textured flour ground from the whole wheat kernel and thus it contains the nutrition of the whole kernel (Kumar et al., 2011).

In Pakistan there are two types of milling sectors. The modern and sophisticated type is the "roller flour mills" which grind approximately $45 \%$ of the total wheat consumed in the country. Flour produced in these mills is generally named as "branded flour". The other type is the "small scale grinders or village based Chakkies" which grinds about $55 \%$ of the wheat flour consumed in the country. These chakkies usually provide flour 
without any certification mark or owner's name (Alam et al., 2007).

After milling, maintaining the storage quality of flour for better shelf life and storage stability is the most considerable factor. Flour's moisture content is very significant regarding its shelf life, as flour with lower moisture have improved storage stability. Moisture is also of big concern for a safe and better storage of cereals as well as their products regarding microbes (Nasir et al., 2003). Various spoilage microorganisms can proliferate on cereal grains and their finished products kept under improper storage conditions (Deibel and Swanson, 2001). Flour is usually considered a safe product microbiologically due to its low water activity (ICMSF, 1998). However, mould growth decreases flour quality significantly. The level of contamination with a variety of microorganisms including yeasts moulds and bacteria as well as the nutritional composition of flours are important parameters that could adversely affect human health (Shobha et al., 2011).

Impurity content is also one of the main parameter that ascertains quality of any product. It always matters a lot in edible products because impurities can be harmful for health and through edible products they can directly affect health of any individual. Whole wheat flour is of great importance as many people around us are consuming it in almost two meals per day. Differences that may exist in the nutrient composition and impurity content of these two forms of flours are of great concern for consumers who always strive for nutritious flour. Therefore this study was initiated to investigate the nutrient, shelf stability and possible impurity content of branded and unbranded whole wheat flour to create awareness among people about the quality of dietary staple which may be helpful for the consumers to choose the better quality of flour.

\section{Materials and Methods}

The present research work was totally performed in the Food \& Biotechnology Research Centre of PCSIR (Pakistan Council of Scientific and Industrial Research), Lahore, Pakistan. Samples of branded and unbranded whole wheat were procured from the general markets of Lahore, Pakistan during August to September period. Before buying selected samples of branded whole wheat flour, seals were properly checked, while before buying selected samples of unbranded whole wheat flour from local chakkies/grinding mills, hygienic conditions were considered. All samples kept at room temperature in sealed bags were evaluated for proximate constituents, iron content, microbiological quality, shelf stability and impurity contents according to the standard recommended methods. All chemicals/reagents used were of analytical grade and purchased from Sigma Chemical Co. (St. Louis, MO, USA) and Merck (Darmstadt, Germany).

Proximate composition. Proximate composition including ash, moisture, crude fat and protein contents were analyzed by the standard methods of AOAC (2012). Moisture content was anticipated by oven drying method at $105{ }^{\circ} \mathrm{C}$ till stable weight. Crude protein and crude fat of samples were examined using Kjeldhal's and Soxhlet's ether extraction methods, respectively. For crude protein, $0.5 \mathrm{~g}$ of sample was digested using 20 $\mathrm{mL} \mathrm{H}_{2} \mathrm{SO}_{4}$ and digestion mixture. Digested sample was then distilled and titrated with $\mathrm{HCl}(0.0143 \mathrm{~N})$. Ash content was estimated in muffle furnace for $6 \mathrm{~h}$ at 550 ${ }^{\circ} \mathrm{C}$. All samples analysis were carried out in triplicate utilizing the standard procedures. Carbohydrates were calculated by difference.

Determination of crude fibre. The fibre value was estimated by the method reported by Ayesha et al. (2002) with few modifications. Fat free (2 g) sample was taken in a beaker $(500 \mathrm{~mL})$ and boiled constantly for $30 \mathrm{~min}$ in $200 \mathrm{~mL}$ of $1.25 \% \mathrm{H}_{2} \mathrm{SO}_{4}$, distilled water was added at frequent intervals to maintain constant volume in the flask. It was then filtered using muslin cloth and then acid was completely removed by washing residue with hot water. Residue was transferred to a beaker and subjected to 30 min boiling with $200 \mathrm{~mL}$ $1.25 \% \mathrm{NaOH}$ and again filtered and washed with hot water to make it alkali free and with alcohol and diethyl ether. It was then transferred into crucible which was dried overnight at $105^{\circ} \mathrm{C}$.

The ash was prepared by placing the crucible in a muffle furnace at $550{ }^{\circ} \mathrm{C}$ for $3-5 \mathrm{~h}$, then it was cooled and weighed. The crude fibre was calculated by the formula:

$$
\text { Crude fibre } \%=\frac{\mathrm{w} 1-\mathrm{w} 2}{\mathrm{w}} \times 100
$$

where:

w $1=$ crucible weight with ash; $w 2=$ crucible weight; $\mathrm{w}=$ sample weight.

Iron content estimation. Known quantity of each sample was digested with $\mathrm{HNO}_{3}: \mathrm{HClO}_{4}(2: 1, \mathrm{v} / \mathrm{v})$ for 
2-3 $\mathrm{h}$ on a heating mantle, filtered through filter $(0.45$ $\mu \mathrm{m}$ pore size, filter type: HA, Millipore Corporation, Bedford, Massachusetts, USA) and then final volume was made i.e. $100 \mathrm{~mL}$ with distilled water. Iron was estimated by spectrophotometric method of AOAC (2005).

Microbial quality estimation. Microbial quality of the selected samples was determined by finding the yeast and mould count by dilution plating method of FAO (1992).

Shelf stability estimation. Stability of selected samples was determined by investigating the moisture and fat acidity content using the standard methods of AOAC (2012).

Gluten estimation. Gluten content of the flour samples was estimated utilizing the method of Taneya et al. (2014).

Impurity content estimation. Presence or absence of impurity content in selected samples of branded and unbranded whole wheat flour was indirectly detected by comparing the resultant values of the ash, dry gluten, crude fibre, yeast and mould count with the standards set by PPFR (2011) and with the acceptable levels set by FDA (2013).

Water solubility index (WSI) estimation. The WSI value of branded and unbranded wheat flours was calculated by the method of Asaduzzaman et al. (2013) with few modifications. Dried flour sample $(0.83 \mathrm{~g})$ was mixed with $10 \mathrm{~mL}$ of water in a centrifuge tube $(30 \mathrm{~mL})$ and then centrifuged (Hettich Universal Centrifuge). The mixture was subjected to centrifugation at $4000 \mathrm{rpm}$ (RCF 1950) for $30 \mathrm{~min}$ and the supernatant was poured into a Petri-dish and dried at $70{ }^{\circ} \mathrm{C}$ till constant weight. It was then cooled and weighed and WSI value was determined by the following formula:

$$
\text { Water solubility index }(\%)=\frac{w 1-w 2}{w} \times 100
$$

where:

w1 $=$ Petri dish and dried liquid weight; $w 2=$ Petri dish weight (empty); $\mathrm{W}=$ Dried sample weight.

Statistical analysis. Analysis was performed in triplicate and standard errors were calculated for all results. All data collected were analyzed using one way analysis of variance (ANOVA) to determine significant differences $(\mathrm{p}<0.05)$ among the means. All statistical tests were carried out using the Statistical Package (SPSS, 1997).

\section{Results and Discussion}

The present study was planned to determine the nutrients and impurity content in branded and unbranded whole wheat flours along with the assessment of physical parameters, stability and microbiological quality.

Physical characteristics. Physical characteristics of branded and unbranded wheat flours including foreign particles, colour, aroma, consistency and appearance were examined among all samples. In few of the fine wheat flour samples foreign particles were observed. The colour of all studied samples was white except one that is pale in colour (Sample-I). The texture was soft and particles were fine except one sample I that was felt bit coarse in texture. Smell and appearance of all flour samples were good collected from local market of Lahore (Table 1). Our findings are well in accordance with the results of Udofia et al. (2013) that the texture, colour and taste of wheat flour are significant physical attributes, affecting the overall acceptability of flours. Such substantial parameters are quite vital in estimating the quality of wheat flour.

Proximate analysis. Proximate analysis results of branded and unbranded wheat flours are presented in Table 2. After conducting the research and the collected data was compared with standard values of PPFR (2011) and FDA (2013), following significant findings were obtained.

Moisture content. The moisture value of flour is vital regarding its shelf stability, as flours with lower moisture have better storage stability (Nasir et al., 2003). The results of Table 2 showed that the moisture value in branded whole wheat flours was found from 8.28$10.45 \%$ and in unbranded whole wheat flours the moisture content significantly ranged from $6.67-8.44 \%$ which are in accordance to the permissible limit that is $\leq 13 \%$ as set by PPFR (2011).The results are consistent with the studies of Arif et al. (2010) who found variation from $5.46-11.47 \%$ in the moisture content of wheat flour. It is difficult to analyze exact moisture value in food items as water in them is present in three unusual forms i.e., bound water (crystallization water or as hydrate), adsorbed water (physically bound to the surface of the food ingredients) and free water. The free water is mainly lost by evaporation. Moisture values may take account of other volatile substances like essential oils/ 
volatile acids or amines. Flour moisture of $>13 \%$ is likely to be attacked by germs and insects. Flours with highest moisture value cannot be stored for long period. The low moisture content of wheat flour enhances its storage stability by avoiding mould growth and other biochemical reactions (Singh et al., 2005). Hence the flours were of fine quality with moisture values well below the maximum limit that is $\leq 13 \%$ as set by PPFR (2011). Generally the water activity of dry flour is too low to support the growth or toxin production by molds, but changes in the moisture content even from 1 to $2 \%$ could be sufficient for the growth of molds and ultimately the toxin productions. Therefore, the low moisture content of the soft wheat flours extends the shelf life of the final product without any microbiological deterioration.
Ash content. The findings of the current study (Table 2) indicated that the ash content of branded and unbranded whole wheat flour ranged from $0.71-1.55 \%$ and $1.53-$ $1.64 \%$, respectively. The results revealed that the ash content of branded whole wheat flour lied within the permissible level ( $\leq 1.5 \%)$ as set by PPFR (2011) except brand $\mathrm{D}$. This finding is in close agreement with $1.40 \%$ and $1.00 \%$ ash in refined wheat flour as reported by David et al. (2015). Ash is the measurement of the mineral content and is used for the quality of flour in different varieties (Moreland and Chris, 2011). On the other hand ash content of some selected samples of unbranded whole wheat $(\mathrm{G}, \mathrm{H}$ and $\mathrm{I})$ revealed contamination as the ash content (1.53-1.64\%) was above the permissible level $(\leq 1.5 \%)$ set by PPFR (2011). Wheat ash is typically present in its bran compared with its

Table 1. Physical characteristics of branded and unbranded whole wheat flours $(n=3)$

\begin{tabular}{llllllll}
\hline \hline $\begin{array}{l}\text { Samples } \\
\text { identification }\end{array}$ & Description & Foreign particles & Colour & Smell & Texture & Appearance & Impurity \\
\hline A & Branded & No & No & White & Good & Soft/fine & Good \\
B & Branded & White & Good & Soft/fine & Good & ND \\
C & Branded & No & White & Good & Soft/fine & Good & ND \\
D & Branded & No & White & Good & Soft/fine & Good & ND \\
E & Branded & No & White & Good & Soft/fine & Good & ND \\
F & Unbranded & No & White & Good & Soft/fine & Good & ND \\
G & Unbranded & No & White & Good & Soft/fine & Good & ND \\
H & Unbranded & No & White & Good & Soft/fine & Good & ND \\
I & Unbranded & Yes & Pale & Good & Coarse & Good & Detected \\
J & Unbranded & Yes & White & Good & Soft/fine & Good & Detected \\
\hline \hline
\end{tabular}

$\mathrm{ND}=$ not detected

Table 2. Nutritional composition of branded and unbranded whole wheat flours $(n=3)$

\begin{tabular}{|c|c|c|c|c|c|c|c|}
\hline Samples & Description & Carbohydrate & Protein & Fat & Fibre & Ash & Moisture \\
\hline identificat & & & & $(\%)$ & & & \\
\hline A & Branded & $74.70 \pm 0.17$ & $10.50 \pm 0.04$ & $1.76 \pm 0.02$ & $1.88 \pm 0.00$ & $1.49 \pm 0.18$ & $9.67 \pm 0.135$ \\
\hline B & Branded & $75.13 \pm 0.03$ & $10.72 \pm 0.02$ & $2.00 \pm 0.01$ & $1.92 \pm 0.02$ & $1.44 \pm 0.27$ & $8.78 \pm 0.230$ \\
\hline $\mathrm{C}$ & Branded & $77.24 \pm 0.18$ & $10.11 \pm 0.04$ & $1.80 \pm 0.02$ & $1.07 \pm 0.04$ & $1.50 \pm 0.14$ & $8.28 \pm 0.030$ \\
\hline $\mathrm{D}$ & Branded & $78.48 \pm 0.09$ & $9.14 \pm 0.10$ & $1.48 \pm 0.06$ & $1.02 \pm 0.03$ & $1.55 \pm 0.13$ & $8.34 \pm 0.130$ \\
\hline $\mathrm{E}$ & Branded & $75.23 \pm 0.03$ & $10.60 \pm 0.09$ & $1.05 \pm 0.22$ & $1.97 \pm 0.00$ & $0.71 \pm 0.21$ & $10.45 \pm 0.07$ \\
\hline $\mathrm{F}$ & Unbranded & $76.73 \pm 0.16$ & $10.79 \pm 0.01$ & $2.03 \pm 0.01$ & $1.07 \pm 0.01$ & $1.53 \pm 0.06$ & $7.80 \pm 0.16$ \\
\hline G & Unbranded & $75.61 \pm 0.02$ & $10.32 \pm 0.04$ & $2.16 \pm 0.02$ & $1.84 \pm 0.00$ & $1.63 \pm 0.03$ & $8.44 \pm 0.12$ \\
\hline $\mathrm{H}$ & Unbranded & $78.60 \pm 0.11$ & $10.08 \pm 0.04$ & $1.52 \pm 0.12$ & $1.07 \pm 0.03$ & $1.62 \pm 0.03$ & $7.21 \pm 0.07$ \\
\hline I & Unbranded & $76.60 \pm 0.28$ & $11.26 \pm 0.04$ & $2.17 \pm 0.03$ & $1.67 \pm 0.22$ & $1.64 \pm 0.07$ & $6.67 \pm 0.05$ \\
\hline $\mathrm{J}$ & Unbranded & $77.74 \pm 0.22$ & $10.11 \pm 0.09$ & $1.83 \pm 0.01$ & $1.56 \pm 0.21$ & $1.53 \pm 0.07$ & $7.26 \pm 0.10$ \\
\hline PPFR valu & - & NA & NA & NA & $2.1-2.5$ & 1.5 & 13 \\
\hline
\end{tabular}

PPFR $=$ Punjab Pure Food Rules Standards (2011), Pakistan; NA = not available in PPFR 2011. 
flour. Therefore, lower flour ash content reflects less contamination with wheat bran (Kim and Flores, 1999). This study supported the concept that the ash content within the permissible range suggests purity of wheat flour due to the presence of bran of the wheat kernel in flour. However, excessive ash content in flour suggests contamination of flour.

Crude protein content. Data presented in Table 2 showed that the crude protein content ranged from 9.14$10.72 \%$ and from $10.08-11.26 \%$ among branded and unbranded samples of whole wheat flour, respectively. The variation in the crude protein content of branded and unbranded whole wheat flour depends on the variety of protein ground to flour. The findings of the present study are in agreement with the research results of Siddiqui and Chowdhury (2013) and Arif et al. (2010) who reported variation from 9.30-12.43\% and 9.13$11.36 \%$ in wheat flour. Wheat flour protein made an immense input to the rheological property of dough prepared by wheat flour and therefore the least change in its protein content or protein chemical structure considerably changes rheological and bread making properties of the dough (Moreland and Chris, 2011). The protein content of wheat flour is the basis for determining the quality of the flour and is vital for the functions and features of the final product (Moreland and Chris, 2011). The crude protein content differences can be attributed to the geographical location. Soils with high nitrogen levels can influence protein levels. Different varieties of wheat called "clean", "white", "black" or "hard" if they have a high percentage of protein and called "soft" or "weak" flour if the protein content is low. Hard flour is high in protein $(12 \%$ to $14 \%$ ) and due to flexibility it holds its shape well when cooked (Batool et al., 2012).

Crude fat content. The finding of the present work also revealed that the crude fat content in branded and unbranded whole wheat flour ranged significantly from $1.05-2.00 \%$ and $1.52-2.17 \%$, respectively. Wahab et al. (2014) and Victor et al. (2013) found 1.60\% and 1.8\% fat in whole wheat flour, respectively. Our results are also well justified by the studies of Arif et al. (2010) who reported variation from $1.43-2.40 \%$ in the fat content of different iron fortified wheat flours. Soft wheat flours have higher (1.33\%) fat content (David et al., 2015). The differences in fat content may be due to location and varietal differences. Diets with high fat content contribute significantly to the energy requirement for humans. High fat content of soft wheat flour in this study would make it a better source of fat. High fat flavours are also good for flavour enhancers and useful in improving palatability of foods in which it is incorporated (Aiyesanmi and Oguntokun, 1996).

Crude fibre content. The crude fibre content in branded and unbranded whole wheat flours ranged significantly from $1.02-1.97 \%$ and $1.07-1.84 \%$, respectively. The results revealed that the fibre content of branded and unbranded whole wheat flours did not lie within the standard range (2.1-2.5\%) as set by PPFR (2011). The results are justified by the studies of Arif et al. (2010) who reported variations of $1.12-2.37 \%$ in the fibre content of wheat flour. Wahab et al. (2014) also found $2.13 \%$ fibre content in whole wheat flour. Jutt et al. (2015) and David et al. (2015) also reported a very low ( 0.10 to $0.55 \%$ and $0.51 \%$, respectively) content of fibre in samples of fine wheat flour. Low fibre content of the flour may be due to the loss of bran during processing which is main ingredient for fibre. Quality of wheat flour also depends upon the content of fibre in it. Crude fibre helps in the prevention of heart diseases, colon cancer, diabetes etc.

Carbohydrate content. The present study determined that carbohydrate level of branded whole wheat flour ranged from $74.70-78.48 \%$ whereas carbohydrate content in unbranded whole wheat flour ranged from 75.61$78.60 \%$. The outcome of the current study are very well in line with the findings of Arif et al. (2010) that concluded variation in carbohydrate content from 72.73$78.74 \%$ in wheat flour.

Dry gluten content. The dry gluten ranged significantly from $9.52-11.96 \%$ in branded and from $10.69-12.14 \%$ in unbranded samples of whole wheat flour. The outcome of the current study indicate that the dry gluten content of both branded and unbranded whole wheat flour lied within the standard range set by PPFR (2011) that is = $8 \%$. The results findings of our research work are in well accordance with the conclusions of Gulzar et al. (2010); Khan et al. (2009);Daska et al., (2001), who found variations from $9.4-24.5 \%, 9.35-10.84 \%$ and $10.49-13.60 \%$ in the dry gluten content of different wheat varieties, respectively.

Iron content. There is yet no standard value given for the amount of iron in whole wheat flour by PPFR (2011). From the results of Table 3 out of five branded whole wheat flour, iron was found only in Gold and Grains whole wheat flour. The amount of iron in branded samples A and B whole wheat flour was $115.41 \mathrm{mg} / \mathrm{kg}$ 
and $50.76 \mathrm{mg} / \mathrm{kg}$, respectively. Among unbranded whole wheat flour, iron was detected only in whole wheat flour sample I which was $6.65 \mathrm{mg} / \mathrm{kg}$. Iron content detected in branded whole wheat flour was significantly higher than the iron content $(40.16 \mathrm{mg} / \mathrm{kg})$ determined by Nasir et al. (2003) in their studies. Jutt et al. (2015) study result showed that the range of iron content in fine wheat flour varied between 18.2 to $565 \mathrm{ppm}$ which closely resemble to our findings as well as by Masood et al. (2006). This variation of iron content in different branded flours is due to the fortification of the iron during the flour processing while unbranded flours are without any iron fortification. During the study it was also observed that for certain flour mills the iron content does not match to their claim of fortified iron.

Table 3. Other quality parameters of branded and unbranded whole wheat flours $(n=3)$

\begin{tabular}{|c|c|c|c|c|}
\hline \multirow{2}{*}{\multicolumn{2}{|c|}{$\begin{array}{l}\text { Samples Description } \\
\text { identification }\end{array}$}} & \multirow{2}{*}{$\begin{array}{l}\text { Iron } \\
\text { (ppm) }\end{array}$} & Fat acidity & Dry gluten \\
\hline & & & \multicolumn{2}{|c|}{$(\%)$} \\
\hline A & Branded & $115.41+0.22$ & $0.00408 \pm 0$ & $11.96+0.14$ \\
\hline B & Branded & $50.76+0.00$ & $0.00544 \pm 0$ & $11.11+0.04$ \\
\hline $\mathrm{C}$ & Branded & ND* & $0.00610 \pm 0$ & $11.18+0.06$ \\
\hline $\mathrm{D}$ & Branded & $\mathrm{ND}^{*}$ & $0.00476 \pm 0$ & $9.52+0.01$ \\
\hline $\mathrm{E}$ & Branded & ND* & $0.00476 \pm 0$ & $10.70+0.17$ \\
\hline $\mathrm{F}$ & Unbranded & $\mathrm{ND}^{*}$ & $0.00748 \pm 0$ & $10.69+0.12$ \\
\hline $\mathrm{G}$ & Unbranded & ND* & $0.00610 \pm 0$ & $11.09+0.06$ \\
\hline $\mathrm{H}$ & Unbranded & ND* & $0.00816 \pm 0$ & $11.89+0.11$ \\
\hline I & Unbranded & $6.65+0.16$ & $0.00544 \pm 0$ & $12.14+0.04$ \\
\hline $\mathrm{J}$ & Unbranded & ND* & $0.00476 \pm 0$ & $11.05+0.04$ \\
\hline $\begin{array}{l}\text { PPFR } \\
\text { values }\end{array}$ & - & NA & $\leq 0.115$ & $\geq 8$ \\
\hline
\end{tabular}

$\mathrm{NA}=$ not available in relevant standards; $\mathrm{PPFR}=$ Punjab Pure Food Rules Standards (2011), Pakistan; ND = not detected.

Fat acidity content. The results of the current study indicated that the fat acidity levels of both branded (0.00408-0.0061\%) and unbranded (0.00476-0.00816\%) whole wheat flour lied within the standard range (= $0.115 \%$ ) as set by PPFR (2011). The results of the present study are even below than the findings of Siddiqui and Chowdhury (2013) who found fat acidity level from $0.057-0.069 \%$ in whole wheat flour.

Microbial (yeast and mould) count. The findings of the current study indicated that microbial count (Table 4) in the branded whole wheat flour lied within the permissible level set by FDA (2013). Yeast colonies were not observed in branded whole wheat flour whereas mould colonies $\left(0.1 \times 10^{2} \mathrm{cfu} / \mathrm{g}-0.8 \times 10^{2} \mathrm{cfu} / \mathrm{g}\right)$ in branded whole wheat flour lied within the permissible limit $\left(10^{2}\right.$ $\mathrm{cfu} / \mathrm{g}$ ) set by FDA (2013). Yeast colonies in branded whole wheat flour samples were not detected but were high $\left(1.25 \times 10^{1} \mathrm{cfu} / \mathrm{g}-6.4 \times 10^{1} \mathrm{cfu} / \mathrm{g}\right)$ in unbranded whole wheat flour exceeded the acceptable level $(10 \mathrm{cfu} / \mathrm{g})$ but were below the rejection level $\left(10^{2} \mathrm{cfu} / \mathrm{g}\right)$ as set by FDA (2013). It is concluded from the above findings that branded whole wheat flour showed safe microbial activity whereas selected unbranded samples of whole wheat flour had shown higher level of yeast colonies than acceptable level. This may be due to poor processing as well as handling problem. No proper packaging of the unbranded samples may also be one of the reasons for higher microbial load in these samples. Higher levels of yeast colonies more than acceptable limits deteriorate the quality of flour (Victor et al., 2013).

Water soluble index. The water soluble index (WSI) in various branded and unbranded wheat flours ranged from 4.0-7.7\%. WSI of branded samples was 4.0-5.3\%, whereas of unbranded was $5.6-7.7 \%$ (Fig. 1). Water solubility index is reflective of the semi crystalline structure as well as starch particles disruption and water molecules forming hydrogen bonds to the hydroxyl groups of amylose and amylopectin (Eliasson and Gudmundsson, 1996). Saeid et al. (2015) studies reported between $4.33-8.99 \%$ of water soluble index in various branded wheat flours, while investigating the diverse quality parameters of commercially available wheat flours in Bangladesh. Present study revealed that water solubility index of unbranded wheat flour samples is comparatively higher than the branded samples.

Table 4. Microbiological quality of branded and unbranded whole wheat flours $(n=3)$

\begin{tabular}{|c|c|c|c|}
\hline \multirow{2}{*}{\multicolumn{2}{|c|}{$\begin{array}{l}\text { Samples Description } \\
\text { identification }\end{array}$}} & Yeast colonies & Mould colonies \\
\hline & & \multicolumn{2}{|c|}{$(\mathrm{cfu} / \mathrm{g})$} \\
\hline A & Branded & ND & $0.1 \times 10^{2} \pm 0.4$ \\
\hline B & Branded & ND & $0.6 \times 10^{2} \pm 0.2$ \\
\hline $\mathrm{C}$ & Branded & ND & $0.8 \times 10^{2} \pm 0.4$ \\
\hline D & Branded & ND & $0.5 \times 10^{2} \pm 0.5$ \\
\hline $\mathrm{E}$ & Branded & ND & $0.2 \times 10^{2} \pm 0.6$ \\
\hline $\mathrm{F}$ & Unbranded & $2.95 \times 10^{1} \pm 0.05$ & $1.95 \times 10^{2} \pm 0.15$ \\
\hline G & Unbranded & $5.6 \times 10^{1} \pm 0.2$ & $0.1 \times 10^{2} \pm 0.1$ \\
\hline $\mathrm{H}$ & Unbranded & $1.25 \times 10^{1} \pm 0.35$ & $0.6 \times 10^{2} \pm 0.2$ \\
\hline I & Unbranded & $6.4 \times 10^{1} \pm 0.4$ & ND \\
\hline $\mathrm{J}$ & Unbranded & $6.2 \times 10^{1} \pm 0.4$ & $1.8 \times 10^{2} \pm 0.2$ \\
\hline $\begin{array}{l}\text { PPFR } \\
\text { values }\end{array}$ & - & NA & NA \\
\hline $\begin{array}{l}\text { FDA } \\
\text { values }\end{array}$ & - & $10^{2}$ & $10^{2}$ \\
\hline
\end{tabular}

$\mathrm{NA}=$ not available in PPFR 2011; ND $=$ not detected PPFR = Punjab Pure Food Rules Standards (2011), Pakistan; FDA $=$ Food and Drug Agency (2013) USA standard. 


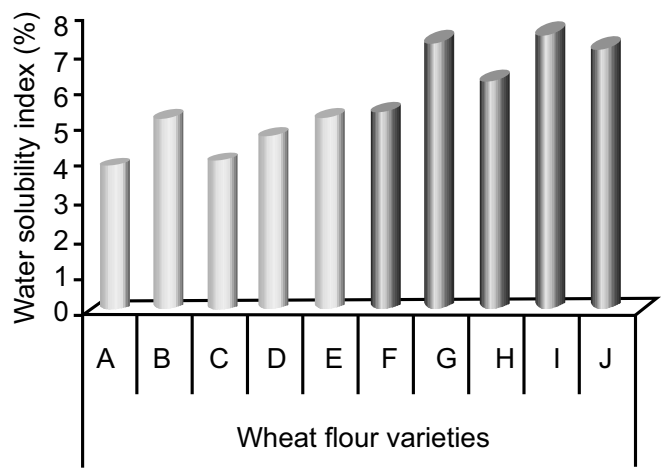

Fig. 1. Water solubility index among five branded (A-E) and five unbranded (F-J) wheat flours.

Impurity content. A product can be considered impure if the nutritional content of the product fails to meet the legal standards for that product set by recognized local and international food and health organizations. The findings of the present study indicated (Table 3) that the results of nutritional and microbial assessment of selected samples of branded whole wheat flour had met the legal standards set by PPFR (2011) and FDA (2013). However, ash content and yeast count of some selected samples of whole wheat flour above legal standards indicated contamination but the results did not support presence of impurity.

\section{Conclusion}

Wheat is an important staple food that is consumed worldwide. This study scrutinized various quality parameters of commercial packed/unpacked flours available in Lahore Pakistan, to help healthier selection of commercial flour samples. It is concluded from the findings that branded and unbranded whole wheat samples showed satisfactory nutritional and storage quality however microbiological quality of branded whole wheat flour was better than unbranded whole wheat flour samples. Moreover, selected samples of branded whole wheat flour neither showed contamination nor presence of impurity. The present study also suggested that the commercially available flours could be consumed safely.

\section{Recommendations}

Although whole wheat flour consumption has been enhanced over a period of time in Pakistan, the government should also generate awareness among people about the health benefits of consuming whole wheat flour to overcome malnutrition through electronic and print media to increase its acceptance. Meanwhile Government should also make sure the availability of safe and nutritious whole wheat flour at affordable price. Pakistani people are malnourished facing iron deficiency in vulnerable population groups. Government should take serious steps to ensure fortification of whole wheat flour with appropriate levels of iron and should conduct excessive awareness campaigns both in rural and urban areas for acceptability of fortified whole wheat flour. There is also a dire need to improve milling conditions to produce good quality flour.

Conflict of Interest. The authors declare no conflict of interest.

\section{References}

Aiyesanmi, A.F., Oguntokun, M.O. 1996. Nutrient composition of Dioclea reflexa seed an underutilized edible legume. Rivista Italiana delle Sostanze Grasse, 73: 521-523.

Alam, S., Hashmi, M.S., Shah, A.S., Khan, U.L. 2007. Comparative storage studies on the organopletic attributes of iron fortified whole wheat flour. Sarhad Journal of Agriculture, 23: 1121-1126.

AOAC, 2012. Cereal Foods, Official Methods of Analysis of AOAC International. $19^{\text {th }}$ edition, Association of Official Analytical Chemists, Maryland, USA.

AOAC, 2005. Official Methods of Analysis of AOAC International. Association of Official Analytical Chemists, Virginia, USA.

Arif, M., Bangash, J.A., Khan, F., Abid, H. 2010. Quality assessment of different iron fortified wheat flours. Pakistan Journal of Biochemistry and Molecular Biology, 43: 192-194.

Asaduzzaman, M., Haque, M.E., Rahman, J., Hasan, S.M.K., Ali, M.A., Akter, M.S. Ahmed, M. 2013. Comparisons of physiochemical, total phenol, flavonoid content and functional properties in six cultivars of aromatic rice in Bangladesh. African Journal of Food Science, 7: 198-203.

Ayesha, S., Abid, N., Anjum, F.M. 2002. Chemical composition of three wheat (Triticum aestivum $\mathrm{L}$.) varieties as affected by NPK doses. International Journal of Agriculture and Biology, 4: 537-539.

Batool, S.A., Rauf, N., Tahir, S.S., Kalsoom, R. 2012. Microbial and Physicochemical contamination in the wheat flour of the twin cities of Pakistan. 
Internet Journal of Food Safety, 14: 75-82.

Belderok, B., Mesdag, J.H., Donner, D.A. 2000. BreadMaking Quality of Wheat: A Century of Breeding in Europe. 432 pp., Springer, New York, USA. ISBN 978-90-481-5493-7.

David, O., Arthur, E., Kwadwo, S.O., Badu, E., Sakyi, P. 2015. Proximate composition and some functional properties of soft wheat flour. International Journal of Innovative Research in Science, Engineering and Technology, 4: 166-172.

Deibel, K.E., Swanson, K.M.J. 2001. Cereal and Cereal Products. In: Microbiological Examination of Foods, P. F. Downes and K. Ito (eds.), pp. 549-552, American Public Health Association, Washington DC, USA.

Duska, C., Damir, K., Dubravka, T., Biserka, P., Jelena, D. 2001. Gluten as a standard of wheat flour quality. Food Technology and Biotechnology, 39: 353-361.

ESP, 2010. Economic Survey of Pakistan. Economic Advisor's Wing, Finance Division, Government of Pakistan, Islamabad, Pakistan.

Eliasson, A.C., Gudmundsson, M. 1996. Starch: Physicochemical and Functional Aspects. In: Carbohydrates in Food, pp. 431-503, $2^{\text {nd }}$ edition, Marcel Dekker, Inc., New York, USA.

FAO, 2013. Pakistan: Review of the Wheat Sector and Grain Storage Issues. Food and Agriculture Organization of the United Nations, Rome. Retrieved from http://www.fao.org/docrep/018/ i3251e.pdf.

FAO/WHO, 1994. Codex Alimentarius Commission, Joint FAO/WHO Programme, vol. 4, $2^{\text {nd }}$ edition, Rome, Italy.

FAO, 1992. Manuals of Food Quality Control: Microbiological Analysis. Food and Nutrition Paper 14/4, Rev. 1, Washington DC, USA.

FDA, 2013. Revised Guidelines for the Assessment of Microbiological Quality of Processed Foods. Food and Drug Administration, Muntinlupa, Philippines.

Gulzar, A., Saeed, M.K., Ali, M.A., Ahmad, I., Ashraf, M., Haq, I. 2010. Evaluation of physiochemical properties of different wheat (Triticum aestivum L.) varieties. Pakistan Journal of Food Sciences, 20: $42-46$.

ICMSF, 1998. Microorganisms in Foods: Microbial Ecology of Food Commodities, pp. 313-346, Blackie Academic and Professional, London, UK.

Jutt, M.A., Farooq, Z., Jutt, S.T., Naeem, N. 2015. Comparison of fine wheat flour quality produced by wheat flour mills of Lahore. Pakistan Journal of Food Science, 25: 182-193.

Khan, M.R., Anjum, F.M., Zahoor, T., Nawaz, H. 2009.
Biochemical and technological characterization of Pakistani spring wheat. Pakistan Journal of Agriculture Sciences, 46: 271-279.

Kim, Y.S., Flores, R.A. 1999. Determination of bran contamination in wheat flours using ash content, color, and bran speck counts. Journal of Cereal Chemistry, 76: 957-961.

Kumar, P., Yadava, R.K., Gollen, B., Kumar, S., Verma, R.K., Yadav, S. 2011. Nutritional contents and medicinal properties of wheat: A review. Life Sciences and Medicine Research, 2011: 1-10.

Masood, S., Nasir, M., Saeed, A., Kamran, S. 2006. Effect of moisture and packaging on the shelf life of wheat flour. Internet Journal of Food Safety, 4: 1-6.

Moreland, C., Chris, H. 2011. Quantitative Analysis of Wheat Flour Using FT-NIR. Thermo Scientific. Madison, WI, USA. 5 pp. httpsL//hosmed.fi/wpcontent/uploads/2016/10/wheat-flour-FT-NIR/pdf.

Nasir, M., Butt, M.S., Anjum, F.M., Sharif, K., Minhas, R. 2003. Effect of moisture on the shelf life of wheat flour. International Journal of Agriculture and Biology, 5: 458-459.

PPFR, 2011. Punjab Pure Food Rules, Department of Health: Government of the Punjab, Pakistan.

Saeid, A., Hoque, S., Kumar, U., Das, M., Muhammad, N., Rahman, M.M., Ahmed, M. 2015. Comparative studies on nutritional quality of commercial wheat flour in Bangladesh. Bangladesh Journal of Scientific and Industrial Research, 50: 181-188.

Shobha, D., Prasanna, K., Puttaramanaik, M.K., Sreemasetty, T.A. 2011. Effect of antioxidant on the shelf life of quality protein maize flour. Indian Journal of Fundamental and Applied Life Science, 1: 129-140.

Siddiqui, A.A., Chowdhury, M.N.A. 2013. Physicochemical and microbiological quality assessment of different popular brands of wheat flour available in Bangladesh. Journal of SUB, 4: 57-65.

Singh, A., Hung, Y., Corredig, M., Phillips, R.D., Chinnan, M.S., McWatters, K.H. 2005. Effect of milling method on selected physical and functional properties of cowpea (Vigna unguiculata) paste. International Journal of Food Science and Technology, 40: 525-536.

Taneya, M.L.J., Biswas, M.M.H., Shams-Ud-Din, M. 2014. The studies on the preparation of instant noodles from wheat flour supplementing with sweet potato flour. Journal of Bangladesh Agriculture University, 12: 135-142. 
Udofia, P.G., Udoudo, P.J., Eyen, N.O. 2013. Sensory evaluation of wheat-cassava-soybean composite flour (WCS) bread by the mixture experiment design. African Journal of Food Sciences, 7: 368374.

USDA, 2014. Grain Inspection Handbook (Book-II), WHEAT, pp. 1-38, Grain Inspection, Packers and Stockyards Administration \& Federal and Grain Inspection Service. Retrieved from http://www. gipsa.usda.gov/fgis/handbook/grain-insp/grbook2/ wheat.pdf.

USDA, 2014. Pakistan: Grain and Feed Annual.
Government of United States. Retrieved from Annual_Islamabad_Pakistan_3-31-2014.pdf.

Victor, N., Bekele, M.S., Ntseliseng, M., Makotoko, M., Peter, C., Asita, A.O. 2013. Microbial and physicochemical characterization of maize and wheat flour from a milling company, Lesotho. International Journal of Food Safety, 15: 11-19.

Wahab, S., Khattak, M.K., Khalil, S.K., Fahim-Ullah. 2014. Effect of cowpea flour supplementation on the nutritive value of whole wheat flour leavened bread. World Journal of Pharmaceutical Research, 3: 4393-4403. 